\title{
AVALIAÇÃO DE TÉCNICAS DE REFINO DE ÓLEO RECICLADO PARA A PRODUÇÃO BIODIESEL
}

\section{EVALUATION OF RECYCLED OIL REFINING TECHNIQUES FOR BIODIESEL PRODUCTION Carmem Cícera Maria da Silva $^{1^{*}, \& \text { Gustavo Graciano Fonseca }}{ }^{2}$}

${ }^{1}$ Universidade Federal do Espírito Santo, UFES, Brasil. ${ }^{2}$ Universidade Federal da Grande Dourados, Faculdade de Ciências Biológicas e Ambientais. ${ }^{1 *}$ carmemcenos@gmail.com ${ }^{2}$ ggf@ufgd.edu.br

\section{ARTIGO INFO.}

\section{Recebido em: 14.05.2021}

Aprovado em: 23.06.2021

Disponibilizado em: 24.06.2021

\section{Palavras-chave:}

Biodiesel; acidez; rendimento; tratamento.

\section{KEYWORDS:}

Biodiesel; acidity; yield; treatment.

*Autor Correspondente: Silva, C. C. M.

\section{RESUMO}

O óleo reciclado é uma opção de matéria-prima para a produção de biodiesel. Ele apresenta vantagens ambiental e econômica, mas há desvantagens na produção de biodiesel, como a presença de resíduos das reações de oxidação que ocorrem durante as frituras. O óleo reciclado chega ao produtor de biodiesel com estas impurezas e acidez acima do padrão desejado. Desta forma, necessita de tratamentos adicionais, como a neutralização química. Este processo é muito utilizado por indústrias oleaginosas e produtores de biodiesel, mas apresenta desvantagens quando o objetivo é tratar óleos com acidez elevada. Tratamentos ambientalmente corretos e inovadores para os óleos, tem sido alvo de pesquisas recentes visando menores impactos à matéria-prima e formação de resíduos (ou formação de coprodutos de maior valor agregado). Este estudo teve como objetivo apresentar o refino físico como um processo substituto de tratamento aos óleos reciclados no processo de produção de biodiesel, realizando uma avaliação comparativa como o refino químico, através de determinações de rendimento e de parâmetros físicoquímicos. Os resultados obtidos demonstraram que o tratamento de refino físico acarretou uma redução de $32,59 \%$ de índice de acidez, enquanto que o químico foi de $92,11 \%$, ambos em relação ao índice de acidez do óleo inicial. Em contrapartida, o comparativo de rendimento entre as duas técnicas, demonstrou que o físico apresentou um aumento de 51,09\% em relação ao químico, sem causar formação de borra e resíduos. Por meio do refino físico houve a formação de ácidos graxos livres que podem ter várias aplicações industriais na química fina ao contrário do químico.

\section{ABSTRACT}

Recycled oil is a raw material option for the production of biodiesel. It has environmental and economic advantages, but there are disadvantages in the production of biodiesel, such as the presence of residues from the oxidation reactions that occur during frying. The recycled oil arrives at the biodiesel producer with these impurities and acidity above the desired standard. Therefore, it needs additional treatments, such as chemical neutralization. This process is widely used by oilseed industries and biodiesel producers, but it has disadvantages for treating oils with high acidity. Environmentally correct and innovative treatments for oils have been the subject of recent research aiming at lower impacts on the raw material and the formation of residues (or formation of higher value-added co-products). This study aimed to present physical refining as an substitute process for treating recycled oils in the biodiesel production process, performing a comparative evaluation as chemical refining, through determinations of yield and physicochemical parameters. The results obtained showed that the physical refining treatment resulted in a $32.59 \%$ reduction in the acidity index, while the chemical refining treatment was $92.11 \%$, both in relation to the acidity index of the initial oil. On the other hand, the comparison of yield between the two techniques showed that the physicist showed an increase of $51.09 \%$ in relation to the chemical, without causing the formation of sludge and residues. Through physical refining there was the formation of free fatty acids that can have several industrial applications in fine chemistry as opposed to chemical. 


\section{NTRODUÇÃO}

O uso de biodiesel como combustível vem crescendo aceleradamente no mundo inteiro, pois sua cadeia de produção tem um potencial promissor em vários setores, tais como social, ambiental e tecnológico. O biodiesel abre oportunidades de geração de empregos no campo, valorizando a mão de obra rural, bem como no setor industrial, empregando mão de obra especializada na produção do combustível (Campos-Ramirez et al., 2020).

Quanto ao aspecto ambiental, a contribuição também é grande, visto que proporciona uma redução significativa e quantitativa de níveis de poluição ambiental, pois o biodiesel é livre de enxofre e de compostos aromáticos, emite menor índice de particulados, como $\mathrm{HC}, \mathrm{CO}$ e $\mathrm{CO}_{2}$, não é tóxico, é biodegradável, além de ser oriundo de fontes renováveis (Mantovani et al., 2018), gerando uma menor emissão de carbono. Sobre o aspecto tecnológico, testes de desempenho de motores com o uso de $100 \%$ de biodiesel têm se mostrado bastante satisfatórios, em especial por não apresentarem problemas significativos (Barros et al., 2020).

Em relação às matérias-primas para a produção de biocombustível, o Brasil tem uma biodiversidade enorme, o que lhe possibilita desenvolver regiões produtoras de oleaginosas em todo o seu território (Cardoso et al., 2020). As matérias-primas mais utilizadas na produção de biodiesel no Brasil são os óleos de soja degomados, representando cerca de 68,00\%, seguido por gorduras animais. $\mathrm{O}$ óleo reciclado de frituras ainda uma matéria-prima minoritária $(1,57 \%)$ em relação as demais, conforme mostra a Figura 1 (ANP, 2019). É importante destacar que a utilização do óleo de fritura na produção de biodiesel reduz o uso de outras matérias-primas que já estão estabelecidas e consolidadas em outros setores, como alimentício, farmacêutico e cosméticos, evitando concorrência entre estes setores e o processo produtivo de biodiesel (Cardoso et al., 2020).

Figura 1. Monitoramento das matérias-primas utilizadas no processo produtivo do biodiesel brasileiro em 2019.

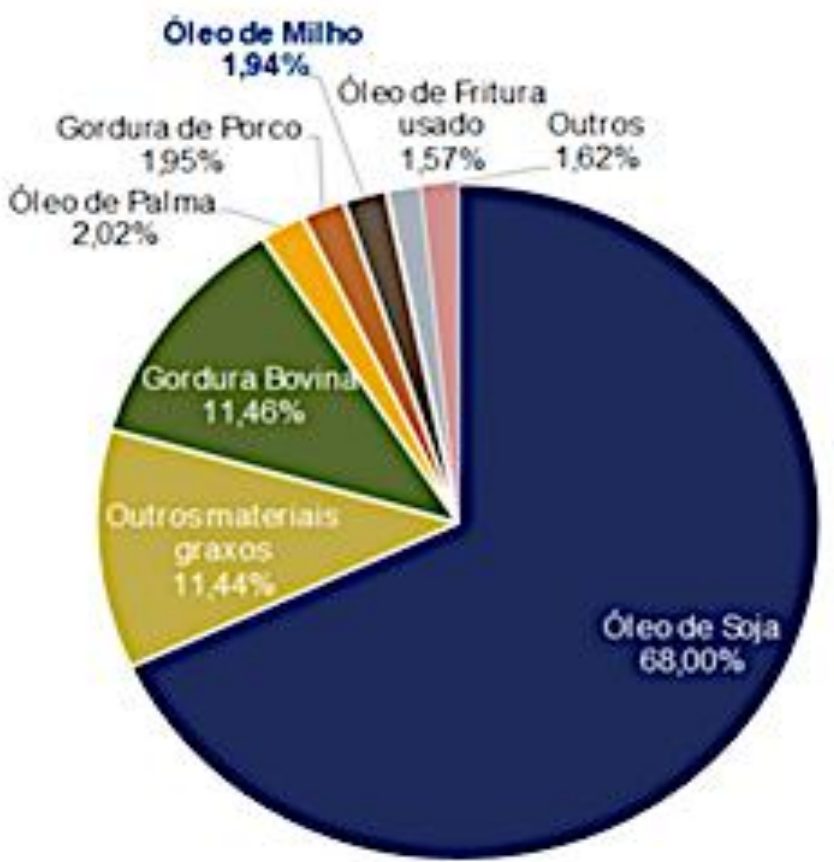

Fonte: ANP, 2019 
Uma das dificuldades para se alcançar a consolidação comercial do biodiesel é o alto custo destas matérias-primas, que compreendem cerca de $80 \%$ do preço final do biodiesel (Galina et al., 2020). Além disso, a composição química, qualidade e rendimento do biodiesel estão diretamente relacionados com os óleos e/ou gorduras utilizados no processo produtivo e cada matéria graxa apresentará sua composição típica de ácidos graxos, bem como suas características, influenciando assim toda a cadeia (Celestino et al., 2020).

Uma opção de matéria-prima que tem se destacado de uma maneira discreta na produção de biodiesel é o óleo reciclado. Há inúmeras vantagens na utilização do mesmo, como exemplo, transformar um possível contaminante ativo aos solos, rios e córregos em biocombustível e a redução de obstrução em tubulações de esgotos ocasionada pelo descarte incorreto do óleo de fritura (Silva \& Heck, 2020).

As estimativas de coleta de óleo residual de fritura (ORF) variam de 2,45 a 8,60 L per capita por ano. Considerando-se que a média 4,85 L de óleo degradado produzidos per capita por ano por uma população média 205 milhões de brasileiros (IBGE, 2019) pudesse ser coletada, seriam em torno de 995 milhões de litros/ano disponíveis para serem convertidos em biodiesel. Se 80\% do óleo de fritura fosse convertido em biodiesel, haveriam 875 milhões de litros/ano (875.000 $\mathrm{m}^{3} / \mathrm{ano}$ ) deste biocombustível. Este volume correspondente a cerca de $22 \%$ da produção acumulada de 3.937.232 $\mathrm{m}^{3}$ de biodiesel no Brasil em 2019 (ANP, 2019).

Esforços têm sido direcionados na busca por novas matérias-primas que consigam reduzir o custo operacional de produção de biodiesel, viabilizando um produto que seja economicamente viável para ser competitivo comercialmente em leilões da ANP. Entre os potenciais candidatos está o óleo reciclado, cujo custo pode ser cerca de 1,5 a 3 vezes mais baixo comparado a outros óleos. Porém, o principal impacto negativo do óleo reciclado na produção de biodiesel é a sua qualidade, que devido aos vários processos oxidativos durante as frituras e as precárias condições de armazenamento, chegam ao produtor bem aquém dos parâmetros adequados a submetê-lo a condições de transesterificação (Khan et al.,2019).

Atualmente a maioria dos produtores de biodiesel não possuem uma estrutura operacional que detenha um tratamento adequado ao óleo reciclado. Devido ao seu baixo custo de implantação e o curto tempo de montagem do processo, o refino químico vem sendo utilizado como tratamento para o óleo reciclado, já que a sua planta operacional consta com equipamentos de baixa complexidade de operação, como reatores, centrífugas e tanques do tipo pulmão. A elevada demanda por parte das indústrias pela neutralização química, pode gerar para o setor industrial consequências como: risco operacional na elaboração da solução neutralizante, geração de um coproduto de baixo valor comercial (borra) e geração de efluentes. Portanto, obter uma alternativa de neutralização aos óleos e/ou gorduras, com menos impacto à matériaprima e a obtenção de coprodutos de maior valor agregado em substituição aos resíduos formados na neutralização química é um intuito que viabilizaria muito o uso do óleo reciclado na produção de biodiesel (Silva \& Heck, 2020).

Este estudo tem como objetivo comparar dois tratamentos de neutralização, aplicados a óleos vegetais e/ou gorduras animais: o químico e o físico, a partir de óleo reciclado destinado ao 
processo de obtenção de biodiesel, através da avaliação do rendimento e parâmetros físicoquímicos.

\section{MATERIAIS E MÉTODOS}

\subsection{Refino químico e físico do óleo reciclado}

O estudo iniciou-se com uma amostra de óleo de soja reciclado $(50 \mathrm{~L})$ que foi fornecida por um produtor de biodiesel localizado na cidade de Dourados - MS. Este material de estudo é oriundo de ecopontos em grandes centros urbanos, a única informação que é conhecida, é que o lote de onde se originou o material de estudo, foi comercializado por cooperativas que organizam a coleta em pontos de origem nas cidades de São Paulo - SP e Curitiba - PR. As condições de armazenamento na origem são desconhecidas, mas o transporte foi realizado em caminhões tanques e após chegar no destino, o óleo foi descarregado e armazenado em tanques de aço carbono até a etapa para ser transformado em biodiesel. Estabeleceu-se o tratamento por meio de dois tipos de refino o químico, que já é bastante utilizado por indústrias de obtenção e tratamento de óleos vegetais e o físico de baixo uso industrial, mas que teoricamente apresenta amplas vantagens técnicas, operacionais, financeiro e ambientais em relação ao químico (Figura 2).

Figura 2. Esquema utilizado no refino do óleo reciclado

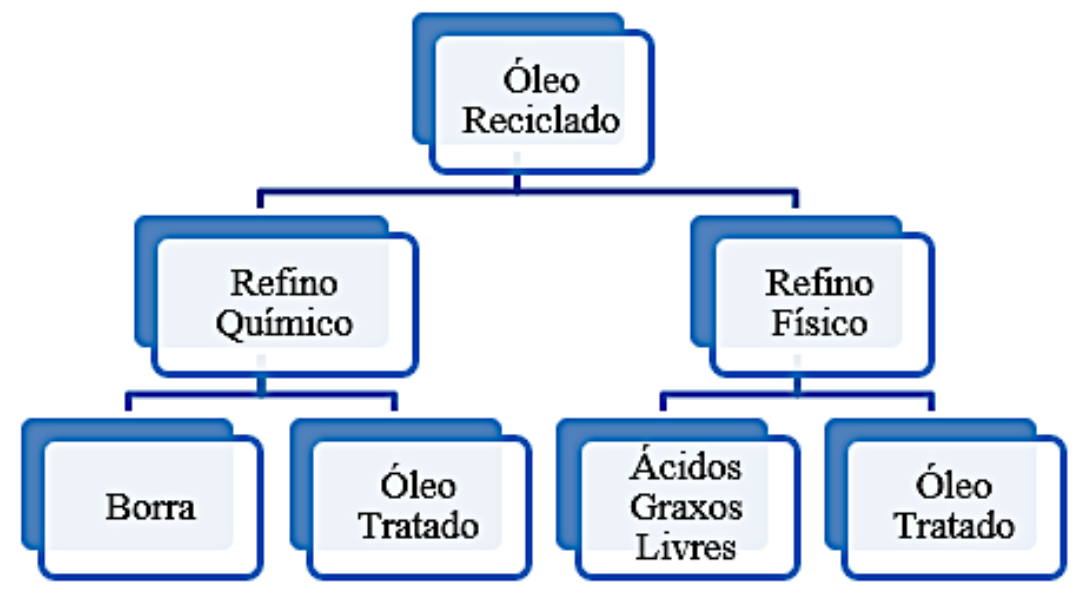

\subsubsection{Refino químico}

Inicialmente analisou-se o óleo reciclado por meio do aspecto (método visual), água e sedimentos (centrifugação) e índice de acidez pelo método (AOCS - Ca 5a 40). Baseando-se no último parâmetro, fez-se o cálculo da quantidade de hidróxido de sódio necessário para adicionar ao óleo durante a reação de neutralização. Iniciou-se esse tratamento com a pesagem de $180 \mathrm{~g}$ de óleo reciclado, em seguida deixou-se sob agitação e aquecimento até chegar a $55^{\circ} \mathrm{C}$, após atingir a temperatura, fez-se a adição de 400 ppm (relação massa do óleo) de ácido fosfórico $\left(\mathrm{H}_{3} \mathrm{PO}_{4} \mathrm{PA}\right.$ Neon, $\left.85 \%\right)$ seguiu-se método de neutralização química otimizado de Moretto e Fett (1988). A mistura reacional ficou sob agitação durante 15 min., após esse tempo, adicionou-se cerca de 15\% de hidróxido de sódio (NaOH PA ACS Dinâmica, 99,0\%), relação massa do óleo, previamente dissolvido em água. A mistura foi mantida sob agitação durante 30 min. (Figura 3A). Após reação a mistura foi decantada para que ocorresse a separação da fase de maior densidade que é a união dos fosfolipídeos, pigmentos, óleo bruto e metais. 
Comercialmente denominada borra e a fase leve, óleo neutralizado e algumas impurezas residuais (Figura 3B).

Figura 3. Neutralização química (A), separação de fases pós reacional (B) e desumidificação do óleo reciclado neutralizado quimicamente
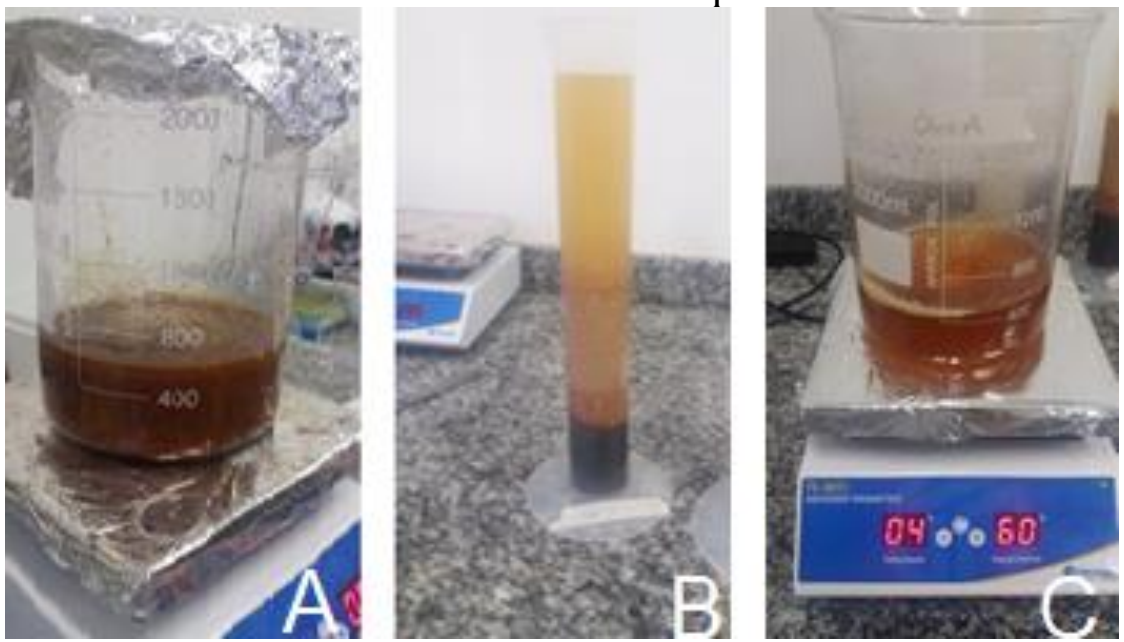

Após decantação a fase sobrenadante foi retirada para iniciar a purificação, que consistiu em duas lavagens com água na proporção de $4 \%$ em relação a massa do óleo. Deixou-se decantar por $24 \mathrm{~h}$ com o intuito de separar a água residual dispersa presente no óleo. Após decantação o mesmo foi desumidificado por $1 \mathrm{~h} \mathrm{a} 110^{\circ} \mathrm{C}$ (Figura 3C). Em seguida realizou-se a caracterização do aspecto, índice de acidez e alcalinidade livre e combinada. Pesou-se a massa final do óleo tratado e calculou-se o rendimento deste tratamento.

\subsubsection{Refino físico}

O óleo reciclado foi utilizado nessa etapa nas mesmas condições iniciais do refino químico. Utilizou-se um evaporador rotativo a vácuo com banho de glicerina PA da marca Buchi, Rotary Evaporador RE 52A (Figura 4). Pesou-se sua massa previamente, em seguida colocou-se no balão de fundo redondo do próprio equipamento, no banho do equipamento adicionou-se glicerina PA e a temperatura foi mantida a $200^{\circ} \mathrm{C}$. Deixou-se sob agitação e evaporação durante 2 h. Em seguida esperou-se esfriar o óleo e pesou-se a massa do óleo e o que ficou no balão do evaporado (ácidos graxos livres e demais impurezas voláteis). Para realização deste procedimento, utilizou-se como método princípios de destilação a vácuo (Cvengros, 1995).

Figura 4. Sistema de destilação, refino físico, aplicado ao óleo reciclado
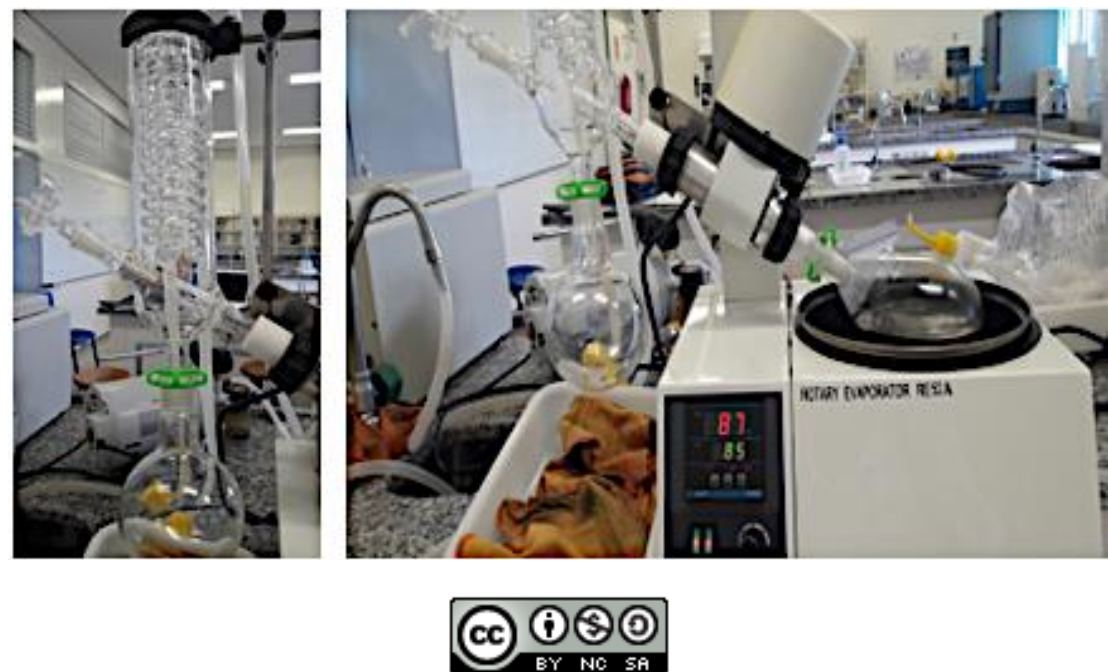


\section{RESULTADOS E DISCUSSÃO}

\section{1 Óleo reciclado}

A matéria-prima utilizada nesta pesquisa, apresentou um aspecto Turvo, índice de acidez de 6,72\%, e água e sedimentos de 0,50\%. Dados característicos de um material oleaginoso fora dos padrões adequados a produção de biodiesel (Lima et al, 2007) e que apresenta condições similares a outros estudos com óleo reciclado (Costa Neto et al., 2000).

\subsection{Refino químico}

Após a neutralização com hidróxido de sódio, houve uma redução de $6.72 \%$ para $0,53 \%$ no índice de acidez do óleo reciclado, demonstrando assim, este método muito eficiente em relação a inserir este parâmetro dentro do mais adequado possível para produção de biodiesel. $\mathrm{O}$ rendimento final desse tratamento foi $41,08 \%$ abaixo do citado na literatura, que é em média 75\% (Mandarino \& Roessing, 2001). Isto justifica-se pela quantidade de borra formada (Figura 5), que consiste na mistura de sabão, óleo arrastado, substâncias insaponificáveis e impurezas. Essa mistura possui um efeito tensoativo que provavelmente resultou no carreamento de parte do óleo tratado, dificultando a separação somente por decantação. As perdas resultantes da neutralização são devidas ao arraste de óleo neutro pela "borra" e pela saponificação do óleo neutro por excesso de solução de hidróxido de sódio empregada.

Figura 5. Borra formada após a neutralização química

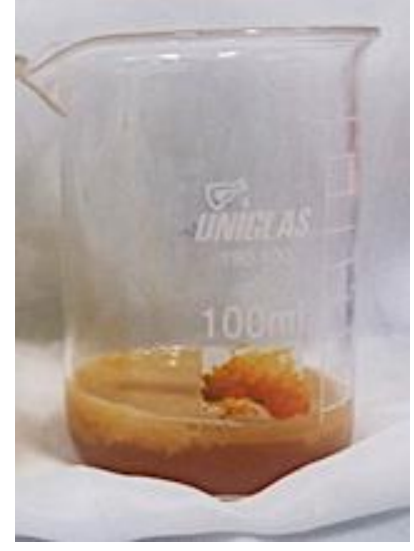

A neutralização alcalina apresenta alguns aspectos desfavoráveis para o refino de óleos: saponificação e arraste de óleo neutro, com resultantes perdas de refinação, dificuldades de se tratar óleos com alta acidez e produção de "borras" com baixo valor comercial, como é o caso do óleo reciclado utilizado como fonte de matéria-prima nessa avaliação de refinos. Pode-se também considerar que o tratamento de um óleo com soda cáustica (hidróxido de sódio) é um método considerado insalubre operacionalmente (Mandarino \& Roessing, 2001). Essas e outras considerações conduziram ao desenvolvimento de sistemas alternativos de refinação. Um dos mais utilizados é a substituição da neutralização com álcalis por destilação dos ácidos graxos livres, o que tornou este tipo de refinação em um processo essencialmente físico.

\subsection{Refino físico}

No refino físico a redução da acidez não foi tão significativa como no químico, como citado anteriormente o óleo inicial apresentava acidez de 6,72\% após destilação houve uma redução

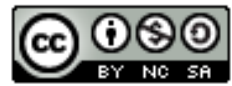


para $4,53 \%$. Observou-se no balão coletor que o líquido evaporado apresentava um aspecto bastante escuro e odor forte característico de ácidos graxos livres e impurezas. A redução do índice de acidez como citada anteriormente não atingiu as expectativas esperadas, o que indica que o sistema utilizado de destilação pode não ter sido tão eficiente, portanto o que abre um leque para estudos futuros com a utilização de um sistema de destilação mais robusto com bombas a vácuo de maior potência.

O rendimento obtido no refino físico foi de $84,00 \%$, em relação ao químico apresentou um aumento de 51,09\%, operacionalmente contabilizando, obteve-se quase o dobro de óleo tratado, algo muito rentável economicamente para as indústrias produtoras de biodiesel que utilizam esta matéria-prima no seu processo produtivo.

De acordo com Mandarino e Roessing (2001), a possibilidade de remover os ácidos graxos livres por destilação baseia-se na considerável diferença entre os pontos de ebulição de ácidos alifáticos e seus ésteres de glicerol. Esses pontos de ebulição variam de acordo com a pressão absoluta. Com a diminuição da pressão, ocorre, também, a diminuição nos pontos de ebulição, tanto dos ácidos graxos quanto dos ésteres de glicerol e, consequentemente, do óleo. Como, por exemplo, o ponto de ebulição do óleo de soja a uma pressão absoluta de $0,05 \mathrm{~mm}$ de $\mathrm{Hg}$ é de $308^{\circ} \mathrm{C}$, e à $0,001 \mathrm{~mm} \mathrm{Hg}$ é de $254^{\circ} \mathrm{C}$, e os pontos de ebulição dos ésteres trilaurina, tripalmitina e triestearina são, respectivamente, $244^{\circ} \mathrm{C}, 298^{\circ} \mathrm{C}$ e $313^{\circ} \mathrm{C}$ à $0,05 \mathrm{~mm}$ de $\mathrm{Hg}$ e $188^{\circ} \mathrm{C}, 239^{\circ} \mathrm{C}$ e $253^{\circ} \mathrm{C}$ à $0,001 \mathrm{~mm}$ de $\mathrm{Hg}$. Além do vácuo, o emprego do vapor de água permite baixar a temperatura de destilação dos ácidos graxos. A refinação física reduz as perdas do óleo e produz, ao invés de "borra", ácidos graxos $80 \%$ a $90 \%$ puros. Entretanto, a contínua melhora na qualidade dos óleos brutos, com decréscimo da acidez, aumenta as vantagens do processo.

\section{CONCLUSÃO}

O comparativo entre os refinos físico e químico do óleo reciclado, demonstrou que o físico não apresentou uma redução no índice de acidez similar ao químico. Mas, em contrapartida apresentou um melhor rendimento, não houve formação de borra e nem resíduos. Em substituição a borra houve a formação de ácidos graxos livres que podem ter vários destinos industriais como ramos farmacêuticos e setores de cosméticos. Uma outra vantagem apresentada foi o não uso de água e ácidos para minimizar o excesso de sabões formados no óleo e consequentemente um efluente que necessitaria de tratamento. A cultura industrial no setor das oleaginosas atualmente ainda opta pela neutralização química pelos motivos citados anteriormente, mas a implantação de um sistema de refino físico requer um investimento maior inicialmente, mas que certamente apresentará inúmeras vantagens técnicas, operacionais e ambientais como já relatado.

\section{AGRADECIMENTOS}

Universidade Federal da Grande Dourados - UFGD, Universidade Estadual do Mato Grosso do Sul - UEMS, FUNDECT, CAPES, CNPq e Biocar.

\section{REFERÊNCIAS}

ANP. Agência Nacional do Petróleo, Gás Natural e Biocombustíveis. (2019). Recuperado de http://www.anp.gov.br/biocombustíveis

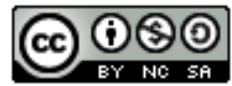


ANP. Agência Nacional do Petróleo, Gás Natural e Biocombustíveis (2015). Recuperado de http://www.anp.gov.br/biocombustíveis

Barros, L. H. C., Purificação, M. C., Campanha, N., Silva, T. F. H., \& Santos, A. G. (2020). Biodiesel do óleo da semente de pinha produzido por reação via aquecimento e ultrassom. South American Journal of Basic Education, Technical and Technological, 7(1), 94-107.

Campos-Ramirez, L., Perez-Sanches, A., Benitez-Legra, A., \& Benitez, I. (2020). Estudio técnico-económico de dos tecnologías de producción de biodiesel a partir de aceite de soya empleando el simulador superpro designer. TecnoLógicas, 23(48), 117-139.

Cardoso, T. S., Santos, R. A., Costa, R. T. T., Aviz, E. O., Araújo, J. F., Silva, A. P., Freitas, M. C. C., \& Correia, L. M. (2020). Uma revisão da utilização de catalisadores heterogêneos para a produção de biodiesel. Brazilian Applied Science Review, 4(1), 240-276. doi:10.34115/basrv4n1- 016

Celestino, K. M., Manual, A. K., \& Jõao, P. G. Synthesis of biodiesel from transportation mufuko oil. Tecnología Química, 40(1), 2020.

Costa Neto, P. R., Rossi, L. F. S., Zagonel, G. F., \& Ramos, L. P. (2000) Produção de biocombustível alternativo ao óleo diesel através da transesterificação de óleo de soja usado em frituras. Química Nova, 23(4), 531-537.

Cvengros, J. Physical refining of edible oils. Journal of the American Oil Chemists' Society (JAOCS), v. 72, n. 10, p. 1193-1196, 1995.

Galina, D., Benedito, V. M., Freitas, R. R., \& Porto, P. S. S. (2020). Análise da influência da temperatura e do tempo na transesterificação direta da Nannochloropsis óculata para produção de biodiesel. Research, Society and Development, 9(7), e655974648. doi:10.33448/rsdv9i7.4648.

Khan, A. M., Safi, A. H., Ahmed, M. N., Siddiqui, A. R., Usmani, M. A., Khan, S.-H., \& Yasmeen, K. (2019). Biodiesel synthesis from waste cooking oil using a variety of waste marble as heterogeneous catalysts. Brazilian Journal of Chemical Engineering, 36(4), 1487-1500.

IBGE - Instituto Brasileiro De Geografia E Estatística. Censos 2019, Rio de Janeiro: IBGE, 2019.

Lima, J. R. O., Silva, R. B., Silva, C. C. M., Santos, L. S. S., Santos Junior, J. R., Moura, E. M. M., \& Moura, C. V. R. (2007). Biodiesel de babaçu (Orbignya sp.) obtido por via etanólica. Química Nova, 30(3), 600-603.

Mantovani, A. C. G., Chendynski, L. T., Salviato, A., Borsato, D., Santana, V. T., \& Di Mauro, E. (2018). Monitoring free radicals formation in the biodiesel oxidation reaction via electronic paramagnetic resonance. Fuel, 224, 255-260.

MAPA, Ministério da Agricultura, Pecuária e Abastecimento. Uso de biodiesel no Brasil e no mundo, $1^{\circ}$ Edição, 2015.

Mandarino, J. M. G., \& Roessing, A. C. Tecnologia para produção do óleo de soja: descrição das etapas, equipamentos, produtos e subprodutos. Documentos / Embrapa Soja, ISSN 1516781X; n. 171, Londrina, Embrapa Soja, 2001.

Moretto, E; Fett, R.; Tecnologia de Óleos e Gorduras Vegetais na Indústria de Alimentos, 1a. ed., Varela: São Paulo, 1998.

Silva, J. D., \& Heck, M. (2020). Panorama da logística reversa do óleo residual de fritura no Brasil. Revista Gestão \& Sustentabilidade Ambiental, 9(especial), 720-739. 